Kristin Wium; Kristian Emil Kristoffersen. Past tense morphology in Cri du chat syndrome: experimental evidence. Clinical Linguistics \& Phonetics 2008, vol 22(4-5), pages 401 - 406

This is an author produced version of the article. The original publication is available at Informaworld

http://www.informaworld.com/openurl?

genre $=$ article $\&$ issn $=0269 \% 2 \mathrm{~d} 9206 \&$ volume $=22 \&$ issue $=4 \&$ spage $=401$

Access to the published version may require journal subscription.

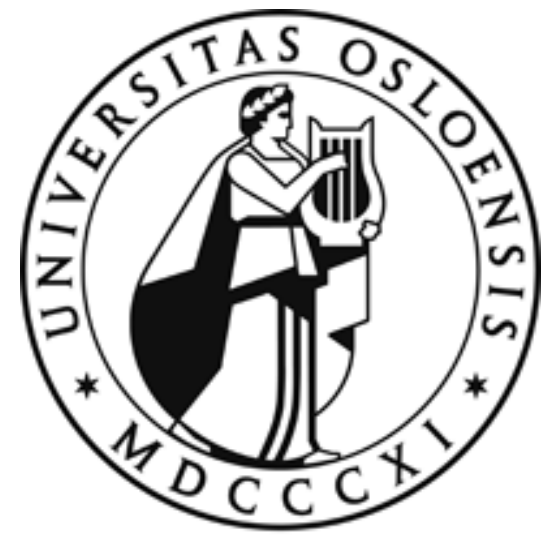


Past tense morphology in Cri du chat syndrome: Experimental evidence.

Published in: Clinical Linguistics \& Phonetics, volume 22, Issue 4 \& 5 April 2008, pages 401 $-406$.

Accepted for publication September 2007 


\title{
Past tense morphology in Cri du chat syndrome:
}

\section{Experimental evidence.}

\author{
Kristin Wium and Kristian Emil Kristoffersen \\ University of Oslo, Norway.
}

\begin{abstract}
It has been observed that persons with cri du chat syndrome (CDCS) have poor language production. However, very few studies have addressed the question whether all aspects of language production are equally afflicted, or whether there are differences between for instance phonological and morphological abilities. The present study was aimed at investigating to what extent persons with CDCS inflect verbs, and, if so, which inflectional patterns in the target language they make use of, and further what kinds of inflectional errors they make. We compared the performance of 3 subjects (aged 11, 15, and 22) with CDCS on a past tense elicitation task. We found that all three subjects inflected verbs. The number of correct responses, however, varied from $28 \%$ to $53 \%$. The majority of errors were overgeneralizations, imitation of input, no response and substitution by semantically related verbs. Keywords: Cri du chat syndrome; past tense morphology; inflectional errors; overgeneralizations
\end{abstract}

\section{Cri du chat syndrome}

Cri du chat syndrome (CDCS) is a rare genetic disorder occurring in approximately 1 in 50 000 live births (Niebuhr, 1978). It is caused by a deletion of material on the short arm of chromosome 5. Clinical features include a high-pitched cry primarily in infancy and childhood, microcephaly, respiratory and cardiac abnormalities (Cornish and Munir, 1998). Other features are moderate to severe intellectual disability, short attention span, and 
hyperactivity, stereotyped, aggressive and self-injurious behaviour (Collins and Cornish, 2002). Carlin (1990) found that hypotonia was present at birth in nearly all her subjects, and approximately half of them continued to have problems caused by hypotonia after infanthood. It was also shown that hypertonia caused problems. Delayed motor development and coordination problems are also seen in most individuals with CDCS (Cornish, K. M., Bramble, D., Munir, F., \& Pigram, J. 1999).

With regard to linguistic abilities, it has been found that delayed speech and language development is very common, but receptive language is in general better than expressive language (Cornish and Munir 1998; Cornish et al., 1999). Moreover, it has been shown that children with CDCS have smaller phoneme inventories as compared to age matched typically developing (TD) children (Kristoffersen, 2003a, 2003b, 2004, 2005).

Very little is known about grammatical production in CDCS. However, based on the fact that the subjects in Kristoffersen (2003a, 2004) all had consonant inventories which were smaller than those of TD 2-year-olds acquiring Norwegian [1], we would expect that grammatical production - i.e. inflections and function words - should be absent or at least very infrequent in the speech individuals with CDCS. Here we address one small aspect of this larger question: to what extent do individuals with CDCS inflect verbs, and how does their performance compare with that of TD children and also that of other clinical groups.

\section{Past tense forms in Norwegian}

Norwegian verbs can be either weak (or regular) or strong (or irregular) [2], cf. table 1 for an overview and examples. Weak verbs comprise $96 \%(n=4900)$ of all Norwegian verbs (Ragnarsdóttir, Simonsen and Plunkett, 1999), whereas strong verbs comprise only 4 \%. 
Weak verbs, which form their past tense by means of a syllabic suffix, can be further divided into two subclasses, one larger ( $n=2700 ; 56 \%)$, and one smaller ( $n=1900 ; 40 \%)$. Verbs in the large class (henceforth the WL class) form their past tense by adding - $a$ /a/ or - et /et/ to the stem, where the choice between the two suffixes is sociolinguistically and stylistically motivated. Verbs belonging to the smaller class (henceforth the WS class), on the other hand, form their past tense by adding -te /te/ or - de /de/. The choice between these two suffixes is phonologically conditioned. The WL class also represents the most productive pattern, since most new verbs entering the language fall into this class (Ragnarsdóttir et al., 1999).

Strong verbs are inflected without a syllabic suffix in the past tense. In addition there is often a modification of the stem vowel. Ragnarsdóttir et al. (1999) make a distinction between seven subclasses of strong verbs in Norwegian. In some of these subclasses there is a high degree of phonological coherence - e.g. all verbs in subclasses 2 and 3 have the same vowel in the infinitive; in other subclasses phonological coherence is low - e.g. in subclasses 1 and 4 the verbs have several different stem vowels in the infinitive.

Table 1: Norwegian verbs

\begin{tabular}{|c|c|c|c|c|c|}
\hline & \multicolumn{2}{|c|}{ Weak verbs } & \multicolumn{3}{|c|}{ Strong verbs* } \\
\hline & WL & WS & & & \\
\hline & 'throw' & 'think' & 'bite' & 'laugh' & 'carry' \\
\hline Stem & kast & tenk & bit & le & bær \\
\hline Infinitive & kast-e & tenk-e & bit-e & le & bcer-e \\
\hline Past & kast-a/-et & tenk-te & beit & lo & bar \\
\hline
\end{tabular}

*The three strong verbs belong to subclass 2 (bite), 4 (le) and 5 (bcere) in Ragnarsdóttir et al. (1999).

\section{Method}

\section{Participants}

Three Norwegian females (P1, P2 and P3) with CDCS participated in the study. They were 11 (P1), 15 (P2) and 22 (P3) years old at the time of the testing. The study is part of a larger 
study on verb production and comprehension (Wium 2006). The participants were recruited from the Cri du chat Support Group in Norway, and the data were collected in the autumn of 2005.

\section{Material}

Our data were collected by means of a picture-based test for eliciting past tense forms of Norwegian verbs. The test is the same as the one used in Ragnarsdóttir et al. (1999), which is an experimental study comparing past tense formation in four-, six-, and eight-year-old Norwegian and Icelandic children. We used the test in a version integrated in a larger test battery (Bastiaanse et al, 2006 [3]) intended for assessment of comprehension and production of verbs and sentences in clinical groups, primarily patients with aphasia.

Sixty verbs were included in the test. The verbs belonged to the two weak classes described above, and the seven subclasses of strong verbs identified by Ragnarsdóttir et al. (1999). Furthermore, the verbs varied with respect to type frequency, token frequency and phonological coherence.

\section{Procedure}

Each participant was tested individually by the first author. P1 and P2 were tested at school and P3 at home. The participants were shown a picture of someone performing an action. The experimenter introduced each picture to the child in the following way (with minor variations): "This is a boy who knows how to - - He is -ing. He did the same thing yesterday. What did he do yesterday?” (from Ragnarsdóttir et al., 1999: 595). The test sessions were recorded into a Sony Digital Audio Tape-recorder (TCD-D10 PRO), using an AKG C 1000 S condenser microphone. 


\section{Results}

\section{Correct responses}

All three participants inflected verbs from all three groups of verbs. However, the share of correct responses varied from 28 \% (P1) to 53 \% (P3), with P2 in between with $47 \%$ correct responses, cf. table (2).

Table 2: Correct past tense responses for all verbs and by verb class.

\begin{tabular}{lccc}
\hline & P1 & P2 & P3 \\
\hline Correct responses all verbs $(n=60)$ & $28 \%$ & $47 \%$ & $53 \%$ \\
WL class $(n=16)$ & $44 \%$ & $63 \%$ & $94 \%$ \\
WS class $(n=17)$ & $18 \%$ & $53 \%$ & $47 \%$ \\
S verbs $(n=27)$ & $30 \%$ & $33 \%$ & $33 \%$ \\
\hline
\end{tabular}

All three participants have more correct responses to WL verbs than to verbs in the two other classes; again with P3 having the highest number of correct responses and P1 the lowest. Furthermore, for P2 and P3 the number of correct responses for the WS class is higher than for the S class. For P1, on the other hand, the opposite situation holds - she produced more correct responses for S verbs than for WS verbs.

\section{Types of errors}

The majority of errors were over-generalizations to one of the other classes, imitation of input, no response and substitution by semantically related verbs. The types and number of errors are shown in table 3.

Table 3: Distribution of error types

\begin{tabular}{lccc}
\hline & P1 & P2 & P3 \\
\hline Total number of errors & $72 \%$ & $53 \%$ & $47 \%$ \\
Over-generalization into the WL class & $14 \%$ & $25 \%$ & $54 \%$ \\
Over-generalization into the WS class & $9 \%$ & $6 \%$ & $11 \%$ \\
No change & $14 \%$ & $3 \%$ & $0 \%$ \\
Imitation & $51 \%$ & $13 \%$ & $36 \%$ \\
No response & $2 \%$ & $41 \%$ & $0 \%$ \\
Wrong verb & $2 \%$ & $13 \%$ & $0 \%$
\end{tabular}


Observe first of all that the distribution of errors differs from one participant to the next. For P1 more than half of the errors were imitations, whereas the largest category of errors for P2 and P3 was no response and generalizations into the WL class, respectively.

For P1 the majority of the overgeneralizations were into the WL class. However, she had the same proportion of errors in the no change category. For P2, on the other hand, the highest number of errors was in the no response category, as a result of her inability to understand the test situation (Wium, 2006). Her overgeneralizations were of two types; the majority fell into the WL class, and the minority into the WS class. Finally, P3 had a considerable share of imitations among her errors (36 \%). Again, there are more overgeneralizations into the WL class than into the WS class. P3 had no overgeneralizations into a strong pattern.

\section{Discussion}

Our results show that individuals with CDCS inflect verbs for past tense, albeit imperfectly (cf. table 3). None of our three participants produced more than $53 \%$ correct past tense forms in our elicitation task. A comparison with four- and six-year-old TD children (Ragnarsdóttir et al., 1999), with children with SLI and with adults (Bjerkan, 2000) reveals that P3's share of correct past tense forms is just above that of typically developing children aged four, whereas both P1 and P2's share of correct responses are well below that, cf. table 4 . 
Table 4: Past tense production in CDCS as compared to other groups

\begin{tabular}{lccccccc}
\hline & P1 & P2 & P3 & $\begin{array}{c}\text { TD } \\
\text { Age 4 }\end{array}$ & $\begin{array}{c}\text { TD } \\
\text { Age 6 }\end{array}$ & $\begin{array}{c}\text { SLI age } \\
6.1-8.8\end{array}$ & Adults \\
\hline \% Correct & $28 \%$ & $47 \%$ & $53 \%$ & $51 \%$ & $72 \%$ & $66 \%$ & $94 \%$ \\
Gen > WL & $14 \%$ & $25 \%$ & $54 \%$ & $44 \%$ & $52 \%$ & $29 \%$ & $10 \%$ \\
Gen > WS & $9 \%$ & $6 \%$ & $11 \%$ & $12 \%$ & $27 \%$ & $25 \%$ & $47 \%$ \\
Gen > S & $0 \%$ & $0 \%$ & $0 \%$ & $2 \%$ & $9 \%$ & $6 \%$ & $17 \%$ \\
No change & $14 \%$ & $3 \%$ & $0 \%$ & $1 \%$ & $2 \%$ & $1 \%$ & $0 \%$ \\
Imitation & $51 \%$ & $13 \%$ & $36 \%$ & $38 \%$ & $7 \%$ & $29 \%$ & $0 \%$ \\
No response & $2 \%$ & $41 \%$ & $0 \%$ & $4 \%$ & $2 \%$ & $3 \%$ & $0 \%$ \\
Wrong verb & $2 \%$ & $13 \%$ & $0 \%$ & $0 \%$ & $0 \%$ & $8 \%$ & $15 \%$ \\
Other & $7 \%$ & $0 \%$ & $0 \%$ & $0 \%$ & $0 \%$ & $0 \%$ & $11 \%$ \\
\hline
\end{tabular}

The majority of the overgeneralizations produced by P2 and P3 fall into the WL class, which is also the case with the TD children and the SLI children. This may be interpreted as an indication that type frequency plays a role in the production of past tense forms for these two participants, which was also found for TD children (Ragnarsdóttir et al., 1999).

One of our subjects, P1, has a large share of no change responses, $14 \%$. The two other participants, in contrast, are similar to the other groups included in table 4 in having fewer than $3 \%$ responses in this category. Here are a couple of P1's responses in this category:

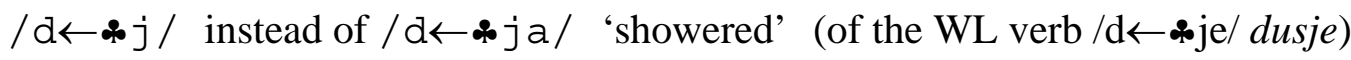

$$
\begin{aligned}
& \text { /^y:t/ instead of /^øjt/ 'shot' (of the strong verb / \&y:te/ skyte) }
\end{aligned}
$$

Ragnarsdóttir et al. (1999) regard no change errors as “as a more general schema or strategy which the child may use when she encounters a problematic verb, something like: 'do as little as possible, as long as the result sounds like a possible past tense (Bybee and Slobin, 1982:274)”. It is plausible that P1's high proportion of no change responses is the result of such a strategy. And it comes as no surprise that it is P1 and not the other two participants that responds with this kind of errors. As far as production is concerned P1 has poor phonological 
abilities (Kristoffersen, 2003a and b) as compared with P2 (which is the same person as subject A in Kristoffersen, 2004) and P3 (Wium, 2006).

\section{Notes}

[1] See Kristoffersen (2007) for a review of research on acquisition of consonants in typically developing Norwegian children.

[2] Norwegian has several dialects. The description of Norwegian in this paper builds Ragnarsdóttir et al. (1999), who describe the dialect known as Urban East Norwegian (UEN). UEN is spoken in the greater Oslo area. See also Endresen and Simonsen (2001) for information on UEN and related dialects of Norwegian.

[3] The version of VOST used in this study is a preliminary version that may differ some from the final version.

\section{References}

Bastiaanse, R., M. Lind, I. Moen, H. G. Simonsen 2006: Verb- og setningstesten (VOST). Oslo: Novus forlag.

Bjerkan, K. M. 2000: Verbal morphology in specifically language impaired children. Evidence from Norwegian. (Acta Humaniora 73). Oslo: Unipub forlag.

Bybee, J. and D. Slobin (1982): Rules and schemas in the development and use of English past tense. Language 58, 265-89.

Carlin, M. E. 1990: The improved prognosis in cri-du-chat (5p-) syndrome. Fraser, W. I. (ed.): Key issues in mental retardation research .London: Routledge, 64-73.

Collins, M. S. R. and K. Cornish 2002: A survey of the prevalence of stereotype, self-injury and aggression in children and young adults with Cri du Chat syndrome. Journal of Intellectual Disability Research 46 (2), 133-140. 
Cornish, K. M. and F. Munir 1998: Receptive and expressive language skills in children with cri-du-chat syndrome 1998: Journal of Communication Disorders 31, 73-81.

Cornish, K. M., D. Bramble, F. Munir and J. Pigram 1999: Cognitive functioning in children with typical cri du chat (5p-) syndrome. Developmental Medicine and Child Neurology 41, 263-266.

Endresen, R. T. and H. G. Simonsen 2001: The Norwegian verb. Simonsen, H. G. and R. T. Endresen (ed.): A Cognitive Approach to the Verb. Morphological and Constructional Perspectives. Berlin - New York: Mouton de Gruyter, 73-94.

Kristoffersen, K. E. 2003a: Development of consonants and vowels in a child with cri du chat syndrome. Journal of Multilingual Communication Disorders 1 (3), 194 -200.

Kristoffersen, K. E. 2003b: Phonological development in a child with cri du chat syndrome (CDCS). Nordlyd 31.3, 519-531. (http://www.ub.uit.no/munin/nordlyd/)

Kristoffersen, K. E. 2004: Consonant production in three children with Cri du chat syndrome. Murdoch, B. E., J. Goozee, B.-M. Wehlan and K. Docking (ed.): 2004 IALP Congress - Proceedings.

Kristoffersen K. E. 2005: Vowel production in the speech of three children with Cri du chat syndrome. Journal of Multilingual Communication Disorders 3 (2), 128-135.

Kristoffersen, K.E. 2007: Norwegian speech acquisition. McLeod, S. (ed.): The international guide to speech acquisition. Clifton Park, NY: Thomson Delmar Learning.

Niebuhr, E. (1978): Cytologic observations in 35 individuals with 5p- karyotype. Human genetics, 42, 143 - 156.

Ragnarsdóttir, H., H. G. Simonsen and K. Plunkett 1999: The acquisition of past tense morphology in Icelandic and Norwegian children: An experimental study. Journal of Child Language 26, 577-618. 
Wium, K. 2006: Preteritumsbøying og verbforståelse hos tre personer med cri du chatsyndrom: Eksperimentelle data. Master thesis at the Department of Linguistics and Scandinavian Studies, University of Oslo. 